\section{Dr. Hellquist, et al reply}

\section{To the Editor:}

We read with interest the letter of Suarez-Gestal, $e a^{1}{ }^{1}$, and we believe that it is useful to briefly discuss possible causes of differences between our study $^{2}$, which reported an interaction between the TYK2 and IRF5 genes, and the report of Suarez-Gestal, et al. It is a common observation that replicating even single-gene association results in complex disorders is not always easy, and largely the same causes that may explain these differences also apply to gene-gene interaction studies.

Some of the common causes for the different results include insufficient power due to small sample sets; phenotypic differences between patient groups in different studies; true population differences, especially regarding allele frequencies in different populations and in particular for genes with multiple risk alleles such as $I R F 5^{3}$; and methodological differences for selection of SNP, genotyping, and statistical analyses.

Finally, current studies mostly ignore gene-environment effects that may be one cause for population differences. Both our smaller study ${ }^{2}$ and that of Suarez-Gestal, et $a l^{1}$ would undoubtedly have benefited from larger sample sets. Our patients may have included a larger proportion of cases ascertained for systemic lupus erythematosus (SLE) through their skin symptoms, as many of our patients were recruited through dermatology services. Corresponding clinical details were not available in the brief format for the Suarez-Gestal study ${ }^{1}$. As an example of the complexity of the interpretations in different populations, in both studies the patients had similar allele frequencies for IRF5 SNP rs10954213, but the difference in risk seemed to depend on quite different allele frequencies in the population control samples. Suarez-Gestal, et al used logistic regression analysis with interaction term as we did, but did not find evidence for interaction in their data. Interestingly, they added a second analysis that allowed a comparison between different models, and discovered that even though it was the additive model that best fit their data, there was no large difference compared to models with interaction (Akaike's Information Criterion $<2$ ). In other words, even though they did not find support for interaction, their data did not exclude an interaction, either.

Taken together, we suggest that the evidence for epistasis or genetic interaction between the TYK2 and IRF5 genes remains tentative. It is highly meaningful to keep looking for gene-gene interactions, especially between genes that for functional or biochemical reasons might well have such effects. Even though recent genome-wide association studies have been hugely successful in unveiling many new risk loci in a number of complex disorders including SLE, the additive effects of the loci do not suffice to explain the overall genetic risks. One solution to the discrepancy might be the existence of important gene-gene interactions. Further studies on the suggested interaction between TYK 2 and IRF5 are warranted, and the question may not become settled until much larger numbers of samples from multiple populations have been analyzed.

ANNA HELLQUIST, MD, Bioscience and Nutrition, Karolinska Institutet, Huddinge, Sweden; TIINA M. JÄRVINEN, MD, Medical Genetics, University of Helsinki, Helsinki, Finland; SARI KOSKENMIES, MD; MARCO ZUCCHELLI, MD; CHRISTINA ORSMARK-PIETRAS, MD, Bioscience and Nutrition, Karolinska Institutet; LINDA BERGLIND, MD, Clinical Research Centre, Karolinska University Hospital; JAANA PANELIUS, MD; TAINA HASAN, MD, Department of Dermatology, Tampere University Hospital, Tampere, Finland; HEIKKI JULKUNEN, MD, Rheumatology, Helsinki University Central Hospital; MAURO D'AMATO, MD; ULPU SAARIALHO-KERE, MD; JUHA KERE, MD, Bioscience and Nutrition, Karolinska Institutet. Address correspondence to Dr. Hellquist; E-mail: anna.hellquist@ki.se

\section{REFERENCES}

1. Suarez-Gestal M, Calaza M, Gonzalez A, and the European Consortium of SLE DNA Collections. Lack of interaction between systemic lupus erythematosus-associated polymorphisms in TYK2 and IRF5. J Rheumatol 2010;37:676-7.

2. Hellquist A, Jarvinen TM, Koskenmies S, Zucchelli M, Orsmark-Pietras C, Berglind L, et al. Evidence for genetic association and interaction between the TYK2 and IRF5 genes in systemic lupus erythematosus. J Rheumatol 2009;36:1631-8.

3. Graham RR, Kyogoku C, Sigurdsson S, Vlasova IA, Davies LR, Baechler EC, et al. Three functional variants of IFN regulatory factor 5 (IRF5) define risk and protective haplotypes for human lupus. Proc Natl Acad Sci USA 2007;104:6758-63.

J Rheumatol 2010;37:3; doi:10.3899/jrheum.090943 